Article

\title{
Web-Based Recommendation System for Smart Tourism: Multiagent Technology
}

\author{
Raheleh Hassannia ${ }^{1}$, Ali Vatankhah Barenji ${ }^{2,3, *}, \mathrm{Zhi} \mathrm{Li}^{2}$ and Habib Alipour ${ }^{1}$ \\ 1 Faculty of Tourism, Eastern Mediterranean University, Famagusta 99450, TRNC, Via Mersin 10, Turkey; \\ raheleh.hassannia@cc.emu.edu.tr (R.H.); habib.alipour@emu.edu.tr (H.A.) \\ 2 Guangdong Provincial Key Laboratory of Computer Integrated Manufacturing System, School of \\ Electromechanical Engineering, Guangdong University of Technology, Guangzhou 510006, China; \\ pierli@foxmail.com \\ 3 Mechatronics Engineering Department, Kennesaw State University, Marietta, GA 30066, USA \\ * Correspondence: abarenji@kennesaw.edu
}

Received: 3 December 2018; Accepted: 30 December 2018; Published: 10 January 2019

\begin{abstract}
The purpose of the study is to design and develop a recommended system based on agent and web technologies, which utilizes a hybrid recommendation filtering for the smart tourism industry. A hybrid recommendation system based on agent technology is designed by considering the online communication with other sectors in the tourism industry, such as the tourism supply chain, agency etc. However, online communication between the sectors via agents is designed and developed based on the contract net protocol. Furthermore, the design system is developed on the java agent development framework and implemented as a web application. Case study-based results considering two scenarios involving 100 customers illustrated that the proposed web application improves the rate of the recommendation for the customers. In the first scenario without disturbances, this rate was improved by $20 \%$ and the second scenario with disturbances yielded a $30 \%$ rate of acceptable recommendation. In addition, based on the second scenario, real time data communication on the system occurred, thus the proposed system supported real time data communication.
\end{abstract}

Keywords: smart tourism; recommendation system; multiagent system; case study

\section{Introduction}

The tourism industry has experienced tremendous growth in recent years. Such a massive leap has been partly attributed to the rapid development of communication and information technology across the globe as well as the widespread use of the internet, which has simplified the process of accessing large amounts of global data from potential customers (tourists) on points of interest, travel plans, and destinations [1]. Currently, e-tourism thrives in both the social and economic sector [2]. In contrast, interim agency-based software plays a crucial role in bridging the gap between the customers and the system by recommending likely holiday packages and exhilarating tours. Furthermore, such software provides assistance to customers within a specified territory [3]. However, in order to assist customers, many software agencies have developed innovative strategies that provide these customers with information that is useful for planning holiday trips and selecting holiday destinations [4-7]. Developing an efficient software agency depends strongly on the recommender system (RS) or filtering approach as well as real-time data communication process [8,9]. In this system, RS plays an important role in improving the customers' level of satisfaction [10]. Generally, RS directly assists customers in finding reputable services, hotels, tours, tickets, restaurants, and others by aggregating and analyzing the demographic data of the customers' reviews [11]. In this system, an analytic technology is used to compute the probability that a customer will purchase a particular holiday package or tour by 
providing recommendations on the right one to purchase. In travel agencies, RS-based software suggested suitable holiday packages (tickets, hotel, tour, time) for the customer. Furthermore, RS helps improve the customer's loyalty and satisfaction by recommending the acceptable option which is more related to the request of customer [12]. RS is a subclass of information filtering system that seeks to predict the "rating" or "preference" a user would give to an item. Therefore, RS is a foundation of advanced technology such as multiagent system, filtering algorithms which is migrated to the smart tourism, in this respect smart applications are the main body of smart tourism in order to used and adopted traditional tourism industry to advanced technologies [13]. Smart tourism is a new buzzword applied to describe the increasing reliance of tourism destinations, their industries and their tourists on emerging forms of Information communication technology (ICT) that allow for massive amounts of data to be transformed into value propositions [14,15]. In smart tourism, RS is used for to develop an autonomous application to improve online shopping and online reservations $[9,16]$. Generally, recommendation systems are classified into four types, which are: content-based filtering $(\mathrm{CB})$, collaborative filtering (CF), knowledge-based filtering (KBF), and hybrid filtering, which is a combination of other types $[17,18]$.

Recently, advanced technologies, such as agent technology, has been introduced to develop the intelligent software by considering a powerful recommendation system [19]. A multiagent system (MAS) is a distributed artificial intelligence system, which embodies a number of autonomous agents for achieving common goals [20] and introduced a new methodology for design and developed smart application. Combination of RS and MAS can be defined as an intelligent-based software agency for the smart industry [21,22]. However, up until now, the tourism industry has been used these technologies for a single purpose, such as the individual selection of ticket, hotel and city tours with considering simple RS on the body [18]. Meanwhile, a lot of tourism agencies don't prefer to using the existing software or web application for recommending tours package to the customer, because they are suffering online communication with the hotels, tours agency, and supplier, which effect to reduces the flexibility and agility of the system and produces more faults [23]. Additionally, if customers want to used web application for reservice tour packages, need to adapted her/his schedule with existing packages and customization of these packages are not possible in the real time manner [24,25], therefore customers and tour agencies must be willing to use the traditional method (i.e., contacting directly the hotel or tour agency) for selecting or arranging appropriate tour packages based on a customer's request [26,27]. Therefore, the existing web application and software agency suffers from customization for the end user, real time data communication between different sectors of the tourism industry and acceptable RS [25]. Generally, based on existing research works in this area, we can highlight current problems of the software agency as follows [24,28-30], and these problems can be improved by the proposed system:

1. The software agency uses offline data for developed tour packages.

2. Each agency and hotel have no autonomous data update for their operation.

3. The software lacks real-time reconfiguration and cannot support customization.

4. There is a lack of a suitable end-user platform and real time reconfiguration on package tours.

5. There is a lack of suitable recommendation-filtering systems for recommending tour packages.

Therefore, to address the existing problems, this paper presents a web agent-based intelligent recommendation application that incorporates real-time data and hybrid-based filtering system into smart tourism industry for recommending tour package based on the customer request. Generally real time communication and autonomous application are first step for achieving smart tourism industry [31]. Therefore, the aim is developed a real-time based web application by considering agent technology and hybrid recommendation filtering mechanism to improve the rate of acceptable recommended tours to the customer. So, this paper contributes to the tourism industry in the following three ways: Firstly, it presents an online autonomous web agency for smart tourism ecosystem, which is based on the established connection amongst all the sectors in the tourism industry. Secondly, it designs 
and develops the system based on the agent technology and hybrid filtering system. Thirdly, it proposes a suitable filtering system for the tourism industry and to realize package customization. Therefore, the novelty of this research work is the design and development of a real-time multiagent-based recommendation system for supporting the smart tourism, which will be used for find appropriate tour package; the main objective of this study is to upgrade and improve the current software agency in the tourism ecosystem, in order to kick start the process of realizing a truly smart tourism industry.

The remainder of this paper was organized as follows; Section 2, literatures review. Section 3, the proposed system based on agent technology was provided. Section 4 discussed the implementation of the proposed system. Section 5 explained the simulation platform and case study. Finally, Section 6 highlighted the conclusion and future work to be considered in this field.

\section{Literature Review}

Nowadays, the tourism industry has a major impact on the economy. And so, the tourism industry is becoming more demanding and complex with multilayered desires and needs [32]. It is flexible, is often experienced when travelling, with high demand for both perfection and diversity. Consequently, the offers to the tourist should be have multiple high-quality options. Furthermore, consumer need improved agile service change with shorter lifetime for the services rendered [33].

In this competitive world, information communication technology (ICT) introduce to tourism industry, and bringing a whole new concept called "smart tourism" to our world [14,15]. Smart tourism refers to the application of ICT for developing innovative tools in the tourism. It supports integrated efforts at a destination to find innovative ways to collect and use data derived from tourism sectors and social connectedness and customers in combination with advanced technologies to increase efficiency, sustainability and experiences [34]. The ICT tools used for smart tourism include internet of things, mobile communication [9], cloud computing, and artificial intelligence [35,36]. The main aim of smart tourism is to improve the service quality [37]. One of the service that has been developed in recent years is the software agency or web-based agency [32]. The primary objective of these agencies is to recommend suitable reservation (ticket, hotel, and tours package), while the secondary objective is to develop a suitable place for communication and information sharing between the customer and the tourism industry [38]. Therefore, we divided the literature review section into two parts. In the first part, we provided definition about filtering methods, and second part focused on the existing research on the field of agency software by considering the agent technology.

Recommender systems have emerged in the e-commerce domain and are developed to actively recommend the right items to online users [10]. Generally, RS are classified into four types: content-based filtering $(\mathrm{CB})$, collaborative filtering $(\mathrm{CF})$, knowledge-based filtering $(\mathrm{KBF})$, and hybrid filtering $[17,18]$. $\mathrm{CF}$ is a filtering approach that utilizes an information filtering technique based on the customer's previous evaluations or history of previous purchases. Therefore, this approach strongly depends on the other customers' information. Without this information, this approach won't recommend any suggestion, which is the major disadvantage of a CF-based system [39]. CF faces two main issues i.e., the sparsity problem and the scalability problem [40]. In contrast to CF, CB analyzes sets of data that have been rated by the individual customer and uses the contents of those data, as well as the provided ratings, to infer a user profile which can be used to recommend additional items of interest [41]. In a CB recommender system, keywords are used to describe the items and a user profile is built in order to indicate the type of items that the user would prefer [42]. The main drawbacks of the CB system are (1) no suitable suggestions, i.e., the analyzed content does not have enough information to distinguish between items the customer would like or not like, and (2) content must be encoded with meaningful features. Moreover, the demographic data are subcategorized under the $C B$, and this is aimed at grouping customers based on their individual attributes with respect to the stereotypical class to which each belongs to. Therefore, the customer's profile is composed of his or her demographic characteristics, which signifies the class to which he or she belongs. However, sparsity exists with respect to the user profile's demographic data [43]. KBF is based 
on the accumulated facts of the customer's inclinations and needs; functional knowledge, meaning that the acquired information on how a particular item meets a user's requirement, is vital for executing this action. As a result, a correlation can be drawn between the likely recommendation and the customer's needs. Another important piece of information connected to the knowledge-based approach is the ontology-based user profiling [44]. For example, Quickstep is a system recommendation platform that assists researchers by recommending online research papers. This is achieved by generating a model of the user's interests with respect to the ontology of the research paper's topics [45]. To gain mastery over the difficulties that confront these well-known methodologies, which are used to make recommendations as well as filter out the positive aspect of these methodologies, some researchers have chosen to combine them and named it hybrid filtering [46]. Therefore, hybrid filtering is an approach that combines two or more existing filing methods. The hybrid recommendation approach is broadly accepted in the tourism industry because it fills the gaps that exist in other methods [17].

Agent technology has emerged in the last years as a newer and promising paradigm, which is focused on the modelling, design and development of complex systems and software [47]. It has become a leading area of research in $\mathrm{AI}$ as well as the focus of a number of major initiatives. Agents, and more generally, multiagent systems (MAS) are allowed to model in a realistic way (i.e., Complex, heterogeneous and distributed software and environments), by assigning an agent to each real-world entity involved in the domain. Therefore, agent-based technology has been introduced in the design and implementation of an intelligent software agency by taking into account the various types of RS [48,49]. RS and multiagent-based software have been presented by many researchers as a more optimum alternative $[17,18]$. In last decade, MAS research field has undergone several advancements and has displayed certain features that have offered a specific solution to this problem. In fact, the MAS has been recommended as an appropriate tool to developed and design autonomous application with high level of intelligent and possibility combine with web application [50,51].

In this respect, travel agency software and RS were developed based on MAS by considering the different schemas [49]. An agent-based RS for tourism activity called Turist@ was proposed [48] and the major aim of the proposed RS and, thus, the primary objective of their study, was to help tourists select an appropriate destination for their holidays. And so, the proposed system was developed and used in a case study-based evaluation approach based on the city of Tarragona. As another example, a hybrid RS based on the task-based agent specialization was developed using the KBF and CB for handling incoming travel requests [52]. The travel recommendation request was decentralized by the system into subsidiary tasks and sent to the travel services. Then, agents took up certain tasks and executed them based on the information acquired from past results. Moreover, the authors used a simulation-based validation method for their architecture. Additionally, a hybrid recommendation system using Bayesian networks was proposed, which took into account the CB and CF approach [53]. The effectiveness of the proposed approach was demonstrated with the Movie Lens and IMDB data sets. In another research paper, an online-based recommendation was developed using a Delphi panel and repertory grid techniques [7]. Chiang \& Huang [54] developed a user-adapted travel planning system for personalized schedule recommendation. Also, in this research, the authors considered the dynamic of the plan and proposed a system to be implemented which was based on the prototype model. In another study, numerous user-profiling approaches for a demographic recommender system were explored, discussed, and examined [55-58]. Their developed approach provided numerous alternatives for profiling users in terms of their attribute type, attribute representation, and profiling mannerism. An effective model based on the hybrid approach for improving the quality of the recommender systems for mobile e-tourism was also presented [21].

Based on the literature review provided by authors, the existing recommendation system in the tourism industry developed for specific proposed such as road maps, hotel reservation system, flight booking and etc. Also, existing system used the $\mathrm{CB}$ or $\mathrm{CF}$ filtering method, which was based on an offline data gathering system. Meanwhile real time data communication between tourism sectors were not consider on the existing application. Therefore, tourism industries suffered from the use of 
comprehensive agency applications, which are able to developed tour packages based on real-time data and customer requests. In this respect, this research paper aims to design and develop an agent-based intelligent recommendation software, which helps in covering existing gaps in the tourism industry. The proposed system was developed for recommending tour package to customers by using real-time data and hybrid filtering methods.

\section{Materials and Methods}

It is evident that conventional software or traditional methods employed in the tourism industry for selecting tour packages aren't suitable for smart tourism $[29,59]$ due to issues in real time data communication, real time customization and suitable recommendation filtering approach, which leads to unsatisfied customers by recommending unacceptable tours $[8,21]$. To respond to the aforementioned challenges and issues, it is imperative that intelligent software is designed and developed to meet up with the requirements of the present era of the smart tourism. In this respect, this research serves to provide a solution to this dilemma by proposing a novel intelligent tourism recommendation agency, called the ITRS, by considering hybrid recommendation filtering mechanism as well as real-time data gathered from customers and the tourism supply chain (TSC), with aiming to improve the recommendations rate. Therefore, ITRS need to be autonomous and smart application, we used agent technology for deseing and develop ITRS because it is one of the well-known methodology and tools for design and develop autonomous and smart application. MAS used to design and developed various applications on the different field such as financial markets [60], control system [20], project management [61] and in the many others fields, therefore it is accepted methodology and tools for design and develop ITRS. The architecture of ITRS illustrated in Figure 1 by considering data communication and agents connection.

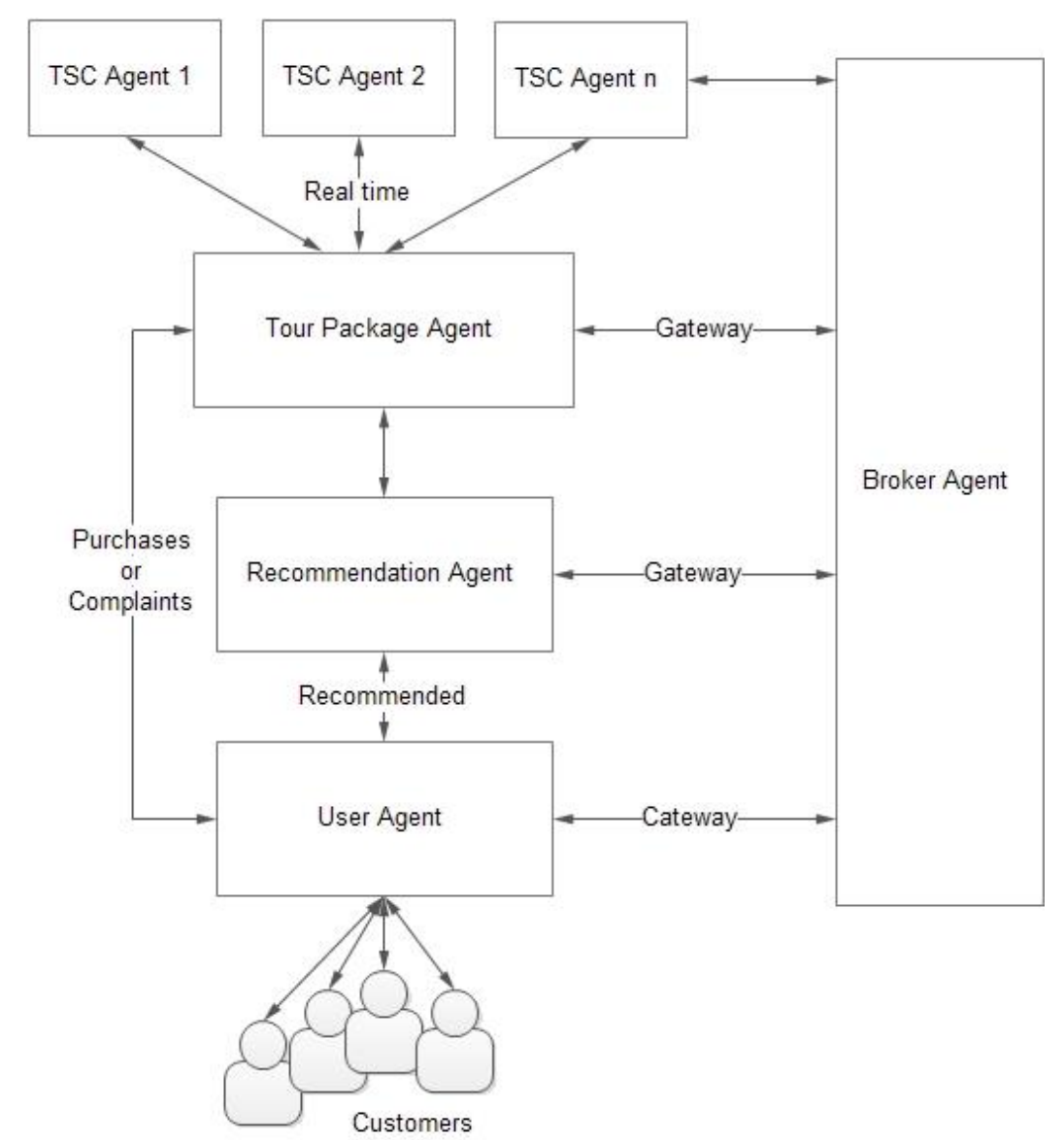

Figure 1. Overall proposed approaches based on agent technology. 
This architecture is developed based on an agent-based model [62] and contains five agents: TSC agent (TSCA), tour package agent (TPA), recommendation agent (RA), user agent (UA), and broker agent (BA). In this application, the agent type is determined based on its functionality and respective application goals. In the proposed software, three groups of agents are exist: the execution agent (EA), information agent (IA), and hybrid agent (HA) (execution and information) [20]. The EA is responsible for carrying out the defined procedures and making the necessary decisions. The IA, as the name implies, is responsible for providing information or data to other agents in order to inform the other agents on the system changes. Table 1 highlights each agent type and the information flow on the agent. Each agent's design and definition are subsequently illustrated in detail.

Table 1. Agent description.

\begin{tabular}{ccccc}
\hline Name & Type & Input & Output & Result \\
\hline TSCA & IA & TSC & TPA & $\begin{array}{c}\text { Real time information from hotels, tour operator and etc. } \\
\text { to proposed software. }\end{array}$ \\
\hline TPA & EA & TSCA & RA & $\begin{array}{c}\text { Create suitable tour packages, purchasing method, } \\
\text { finalization. }\end{array}$ \\
\hline RA & HA & TPA & UA & $\begin{array}{c}\text { Recommended suitable packages for customer based on } \\
\text { hybrid recommendation system. }\end{array}$ \\
\hline UA & IA & Customer & TPA \& RA & Responsible for gathering information from customer. \\
\hline BA & IA & All & All & $\begin{array}{c}\text { Responsible for making gateway between agents for } \\
\text { communication purpose. }\end{array}$ \\
\hline
\end{tabular}

\subsection{Tourism Supply Chain Agent (TSCA)}

The TSCA is responsible for real-time communication and information updates on the proposed system via a web-based user interface. The major responsibility of this agent is to update the system database whenever the hotel managers alters the TSC information. The information accumulated from the hotels as well as other parts of the TSC is usually updated through this agent. Therefore, the TSCA must be able to adapt to the TSC. This agent consists of sub objects categorized in two tiers. The first tier is comprised of the direct suppliers that supplies the tourism services to intermediaries. Examples of typical direct suppliers are parks, shopping centers, hotels, bars and restaurants, handicraft shops, and transportation operators [63]. The second tier is comprised of the supply services or first-tier supplier products, such as the food manufacturer, water and energy suppliers. The updated information through the TSCA directly affects the tour packages in real-time. For this purpose, the TSCA created an interface via the web for tour operators and hotel managers in order to update their information on the system, TSCA follow the semantic based agent communication [64].

\subsection{Tour Package Agent (TPA)}

The TPA creates many types of tour packages according to the variations in the supply and demand of the holidays and tours. These package tours are based on real-time data that has been accumulated from the TSC and customer demand; similarly, a generation of each package tour can be developed for groups or individual customers. Each package is composed of a set of subtours and each customer is expected to like the package. A package contains the modality of the tour, i.e., departure date, price per person, duration, hotel type, and other relevant information. Agent-based technology creates real-time communication between the TPA and two other agents, such as the RA and the TSCA, in order to generate an exceptional package tour this communication on the MAS named as an ACL [65]. This communication is illustrated in the sequence diagram that is shown in Figure 2. From the sequence diagram, we assume that the customer has an initial package in the system, such as advertising-based package; after logging into the application and adding the related information, the updated version of the recommendation packages are sent to the customer's profile. 


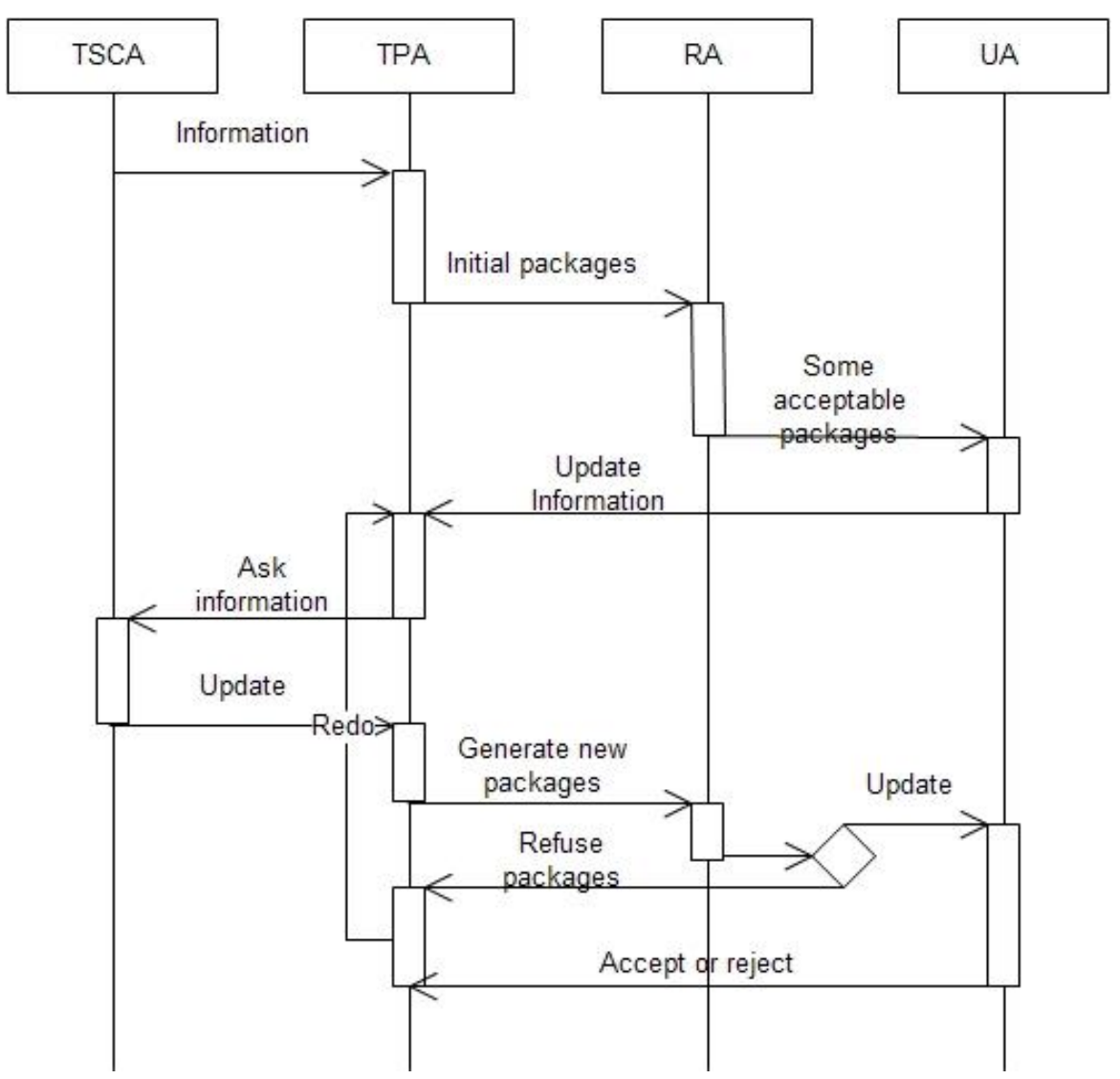

Figure 2. Sequence diagram.

\subsection{User Agent (UA)}

The UA is responsible for providing user interface to end user and hotel managers, it could run on a mobile device through a mobile app or on a website as a web application, enabling the customer to create an account and interact seamlessly with the software. The main aim of the UA is to provide a user interface to the customer by specifying the demographic and evaluation data that would assist in creating a user interface that executes the recommendation and purchasing process. The UA plays a key role in the communication process between the customer and the application. Also, it is vital for the updating of demographic data in the system. Therefore, it must be user-friendly and have high security. Interactions between customer through the UA and other agents are illustrated in Figure 3. The user interface was developed using HTML and AJAX, while the communication between other agents was developed using the HTTPS and JADE gateway.

\subsection{Recommendation Agent}

The major aim of the proposed software is to recommend tour packages that are acceptable and attractive to the customers. Therefore, RA plays an important role towards achieving this objective. RA makes recommendations to customers based on the CF and CB filtering methods; this means that the RA utilizes hybrid approach in the ITRS. The hybrid-based approach and the real-time data that are updated by customers and TSC, helps to improve the RA's performance. The architecture of this agent is illustrated in Figure 4. 


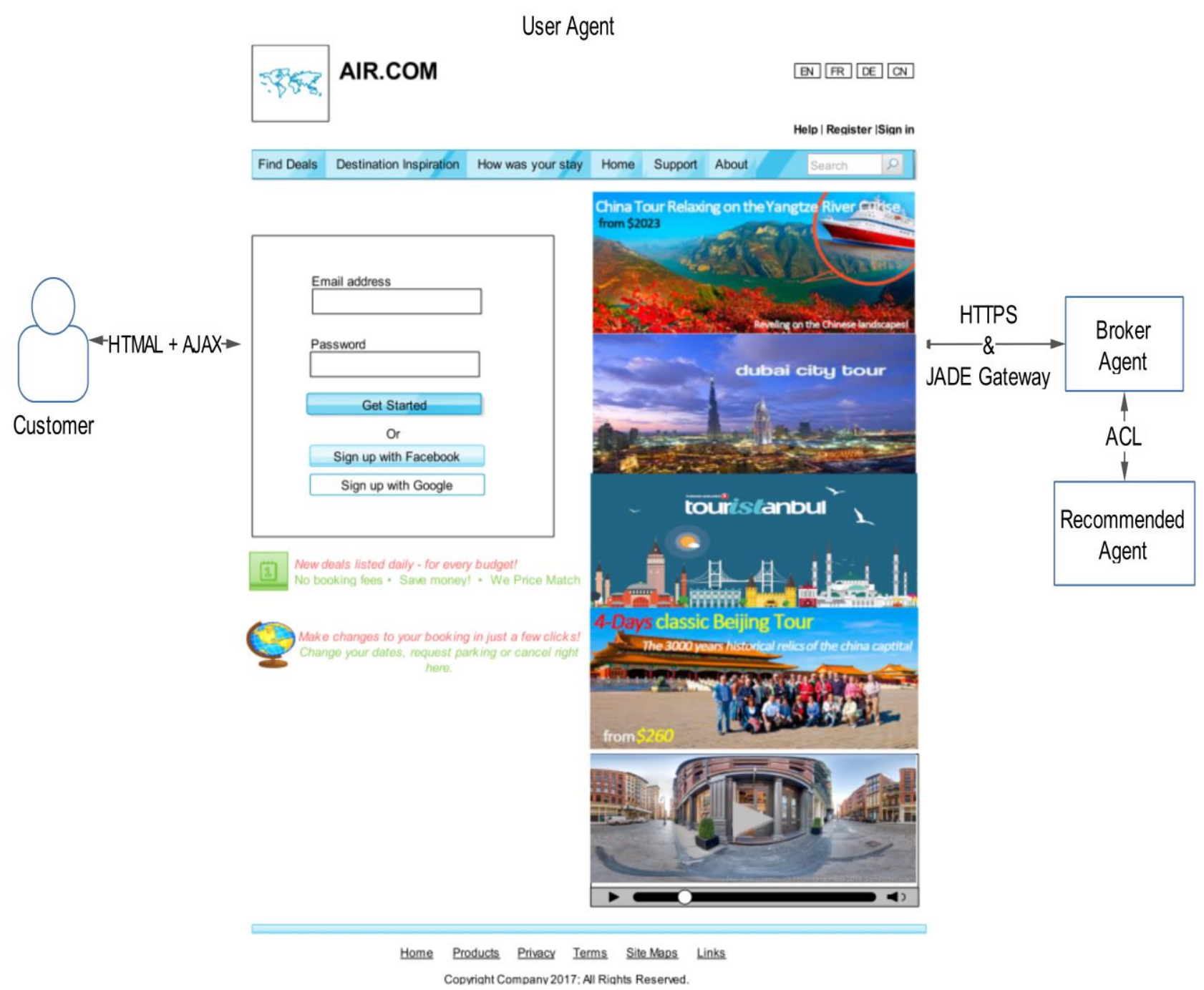

Figure 3. Communication between the customer and recommended agent via user agent. 


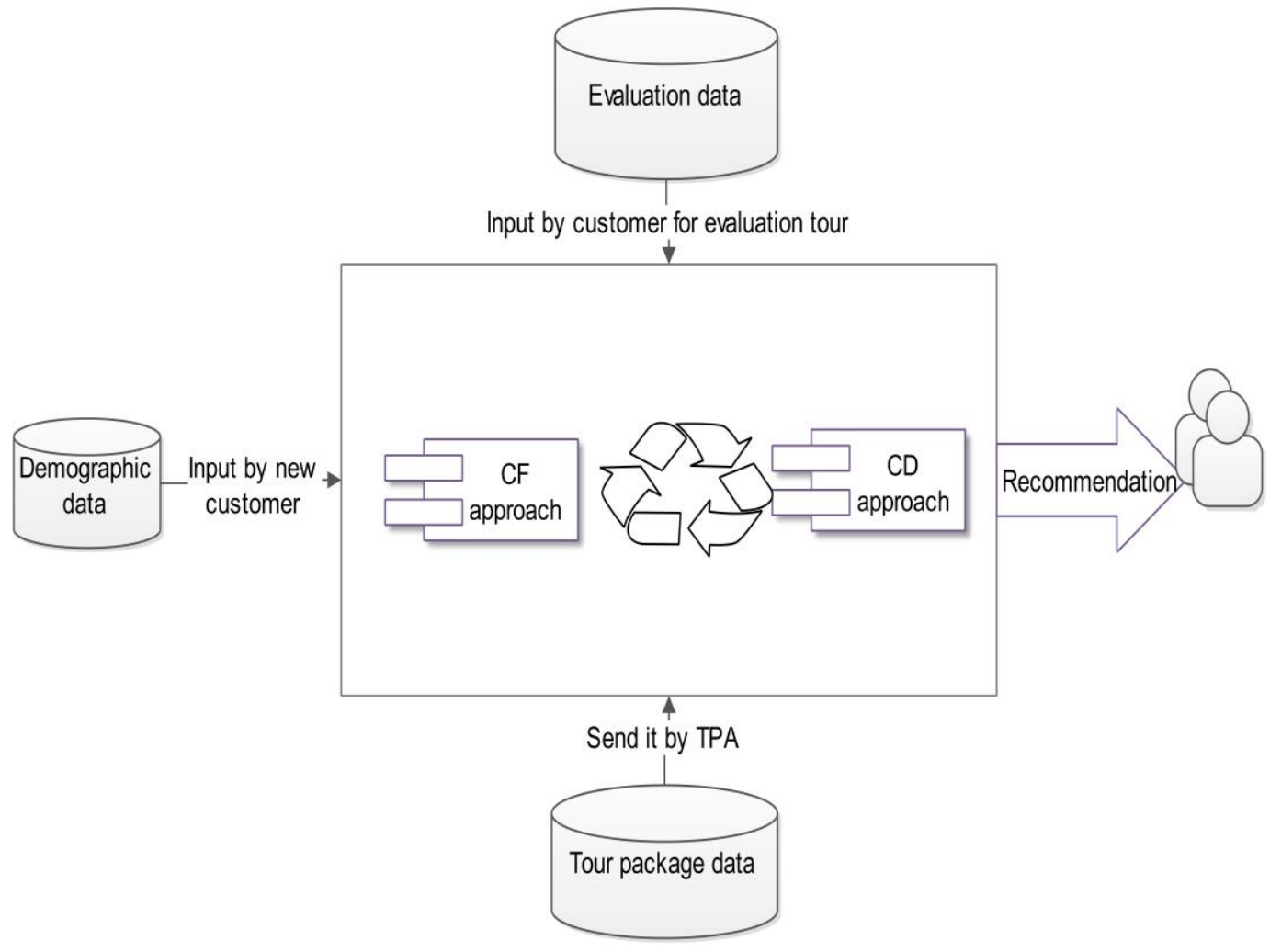

Figure 4. Architecture of recommendation agent.

From Figure 4, it can be seen that RSA uses three types of data as an input; the first one is the demographic data, which is defined by customers in the user profile. This data is categorized into three main classes: personal information, trip information, and favorite information. Such information can be obtained from a brief questionnaire that the customer fills out when the corresponding UA is initialized. Additionally, the favorite information is represented by the qualitative labels and is more focused on the type of trip, based on criteria such as food, city, country, entertainment, and others [66]. Furthermore, updating the demographic data through the UA plays an important role in the system; if the customer does not update his or her information on UA, the system simply recommends any initial or standard package advertised without considering the demographic data. The second data is the feedback of the customers for the tours evaluation. The evaluation result of the customers is sent to the system via UA. Therefore, activities are recommended depending on the customers' interest. Furthermore, we used a text approach for acquiring and updating an evaluation data [67]. Finally, the last data on the RA is the tour package data, which is built up and updated by the TPA using real-time communication with the TSCA such as the available hotels, tours and tickets etc.

To determine the best-recommended packages for the customers, the proposed hybrid filtering approach was utilized, which included both the content-based and collaborative algorithms. Both algorithms enabled the recommended activities to be filtered with respect to their type, language, date of performance, recommended age, price, and supply chain, before being shown to the customer. In the proposed system, recommendations are made on demand and proactively. The first approach was the $\mathrm{CB}$ approach, which follows an association rule leaning towards obtaining knowledge about a customer's preferences and to build on the content-based profile provided [22]. Association rule leaning is a rule-based machine learning method for discovering interesting relations between variables in the large databases. The second approach uses item-based collaborative filtering recommendation algorithms [68] to keep customers interested as well as to improve the customer's satisfaction with the system. Recommendations and suggestions must be quick and agile by making sure each new response is updated on the recommendation model. In other words, the proposed system must be 
able to send a set of recommendations or suggestions within a certain timeframe. Consequently, in the proposed hybrid approach, both approaches (CF and CB) use a matrix $T_{n \times n}$, where $\mathrm{n}$ is the number of tour packages and each $t_{i j} \in T$ represents the total number of sub-items of tour $i$ and $j$ in the same tour package. RA updates the matrix in real time, whenever the data is updated. The RA checks all-possible rules $i \rightarrow j$ by considering the two values ( $P$ is the number of tour items in a tour package):

$$
\begin{gathered}
\text { Support }_{i \rightarrow j}=t_{i j} / P \\
\text { Confidence }_{i \rightarrow j}=t_{i j} / t_{i i}
\end{gathered}
$$

Consequently, by using this method, if a set of $n$ suggestions is requested through the system, the $n$ best recommendations according to the confidence that satisfies the minimum confidence and support requirements are proposed.

Additionally, in the proposed system, collaborative filtering uses the same method and matrix to compute the similarity, which returns the top $n$ most related items.

$$
\operatorname{sim}(i, j)=t_{i j} / \sqrt{t_{i i}} \sqrt{t i j}
$$

The proposed hybrid recommendation mechanism utilizes these formulas, and so, these formulas become implemented based on the code generation on the implantation part. Therefore, these algorithms which are developed based on the existing works $[3,68]$ implemented on the RA agent as code.

\subsection{Broker Agent}

The broker agent is responsible for monitoring and developing a suitable and safe communication platform in the MAS. BA utilizes a contact net protocol $[47,69]$. Additionality, other responsibility of the broker agent is to monitor other agents by sending related information for collaboration and cooperation purpose. In this respect, an agent can cooperate with other agent by sending help signal. Help signal can only be responded to by the agents who come into the preceptory region of the agent who has sent the signal. Mathematically, 'help' signal $S^{t}{ }_{i}$ sent by $i$ th agent for collaborative help in task ' $t$ ' is defined as The BA ensures proper communication among other agents in the multiagent system and so, an ontology was defined in this regard [62]. However, it must be noted that the defined ontology for this current work is more of a knowledge model than a real ontology. Nevertheless, the term ontology has been used by most multiagent environments and it is used here as well [19].

\section{Implementation}

The specified MAS application was executed using the standard in the field-the JADE framework [70] which is compliant with the Foundation for Intelligent Physical Agents (FIPA). JADE offers a group of functionalities, such as a communication protocol and a white or yellow pages service [71]. This simplifies the development of the agent-based applications and the set of auxiliary agents, the agent communication channel, and the agent management system; as a matter of fact, it supports the life cycle management of such an application. The ontology was developed by the Web Ontology Language in collaboration with the Protégé tool [72] for storing heterogeneous information and converting it into XML files. Also, the communication with the customer through a browser was developed using the AJAX platform [73]. The XML-Http Request interface and the JADE-LEAP extension were used to enable execution of agents in portable devices with limited hardware, such as smartphones or PDAs. Figure 3 illustrated technical tools for developed communication between the customer and recommended agent via user agent. We launch proposed web application on the amazon web services, for technical implementation we follow [74] and EC2 was used for computing propose. The proposed hybrid RS was implemented as a code on the EC2, which follows Section 3.4. 


\section{Case Study and Results}

In this experiment, we used a collaborative approach, a content-based approach and a proposed hybrid approach to compare the predicted values generated for the different tours. These filtering approaches were implemented on proposed web application. The experiment was carried out with 100 customers (they were graduate students). The number of customers for evaluation of the proposed platform is an accepted number in this initial step, which makes it easy to eliminate bias on the system [34]. To achieve high quality results, we consider 10 sections, and on each section, 10 customers connected to application in the same time with $20 \mathrm{~min}$ deadline. In the first step customers provided personal information via user agent (Section 3.3) after that based on the request of customer suggested acceptable packages tours to the customer. Therefore, totally experiment took $200 \mathrm{~min}$. Before the launch of the web application, we considered some data as the initial database on the system, this data was gather from Booking.com, Crip.com and Skyscanner.net. We developed 70 summer session tour packages from four different countries, by considering more verity in the system in order to bring possible selection and show the effectiveness of the proposed recommendation system; this number of packages are acceptable number for testing proposed system [68]. In this research, we considered customers from different nationalities respectfully i.e., 20 Iranian, 20 Turkish, 20 Cyprus, 10 Nigeria, 10 Pakistan and 10 Europe. Table 2 illustrates this tour packages in detail by considering the visa requirements.

Table 2. Information about tour packages.

\begin{tabular}{|c|c|c|c|c|c|c|}
\hline $\begin{array}{l}\text { Name of } \\
\text { Country }\end{array}$ & Tours & $\begin{array}{l}\text { Visa Type and } \\
\text { Requirement }\end{array}$ & Airline & Cities & Types of Hotel & Price Range \\
\hline $\begin{array}{l}\text { North } \\
\text { Cyprus }\end{array}$ & 10 & $\begin{array}{c}\text { Visa not } \\
\text { required } \\
\text { Hard electronic }\end{array}$ & $\begin{array}{c}\text { Pegasus, Turkish } \\
\text { Airlines, Mahan Air, } \\
\text { Atlas Global, British } \\
\text { Airlines, etc. }\end{array}$ & $\begin{array}{l}\text { Famagusta, } \\
\text { Lefkosha, Girne, } \\
\text { Guzelyurt. }\end{array}$ & $\begin{array}{l}\text { Five, four and } \\
\text { three-star hotels. }\end{array}$ & $700-3000 \$$ \\
\hline Turkey & 25 & $\begin{array}{c}\text { Visa not } \\
\text { required } \\
\text { Hard electronic }\end{array}$ & $\begin{array}{l}\text { Pegasus, Turkish } \\
\text { Airlines, Mahan Air, } \\
\text { Atlas Global, ATA } \\
\text { Air, and etc. }\end{array}$ & $\begin{array}{l}\text { Antalya, Izmir, } \\
\text { Alanya, Istanbul, } \\
\text { Marmaris, Kemer, } \\
\text { Ankara, Beleck. }\end{array}$ & $\begin{array}{l}\text { Five, four and } \\
\text { three-star hotels. }\end{array}$ & $400-3000 \$$ \\
\hline China & 30 & $\begin{array}{c}\text { Visa not } \\
\text { required } \\
\text { Hard electronic }\end{array}$ & $\begin{array}{c}\text { AirAsia, Thai Air, } \\
\text { China Southern, } \\
\text { Mahan Air, Aeroflot, } \\
\text { etc. }\end{array}$ & $\begin{array}{l}\text { Beijing, Shanghai, } \\
\text { Guangzhou, Dali, } \\
\text { Shenzhen, Xiamen, } \\
\text { Nanjing, Dalian. }\end{array}$ & $\begin{array}{l}\text { Five, four and } \\
\text { three-star hotels. }\end{array}$ & $700-3500 \$$ \\
\hline UAE & 5 & $\begin{array}{c}\text { Visa not } \\
\text { required } \\
\text { Hard electronic }\end{array}$ & $\begin{array}{l}\text { Mahan Air, } \\
\text { Emirates, ATA } \\
\text { Airlines, etc. }\end{array}$ & Dubai, Abu Dhabi. & $\begin{array}{l}\text { Five and four-star } \\
\text { hotel. }\end{array}$ & $400-2500 \$$ \\
\hline
\end{tabular}

In order to have an effective evaluation of the proposed system, we tried considering a variety of possibilities such as different countries, types of hotels, visa requirement and tours, which made it challenging for the proposed system. To consider real-time communication using the TSC, we considered real-time data exchange on the system by the hotel manager via the web user interface as well as real-time communication between the proposed web application and the TSC. Moreover, two different scenarios were presented; in the first scenario, there was no drawback in the system, this meant that the TSC and all parts supported the existing tours (all 70). However, in the second scenario, two packages from Cyprus and three packages from Turkey were deleted via the TPA with respect to TSC communication as result of no vacant rooms. In order to achieve equal evaluation, the proposed system developed for the three filtering approaches and negotiation failure between agents were assumed not to occur. To evaluate and analyze the proposed platform, based on software view two indicators were considered: precision and recall [49]. Generally, precision is the fraction of relevant instances among the retrieved instances, while recall is the fraction of relevant instances that have been retrieved over the total amount of relevant instances [22]. Therefore, both precision and recall can be defined based on an understanding and measure of relevance. Therefore, in this study, Precision 
is defined as a ratio of selected relevant items to the number of total items, and recall is defined as the ratio of selected relevant items to the available total relevant items. Therefore, these two indicates illustrated the capability of the proposed web application based on the accepted rate which is the main aim of this paper, improve the quality of the software agency in order to improve and increase number of customers and agencies which are used intelligent software. For formulation of these indicators this study used [31]. Therefore, our study precision and recall are given by the following formulas.

$$
\text { Recall }=d /(b+c+d)
$$

$\mathrm{b}, \mathrm{c}$ and $\mathrm{d}$ list of possible tour packages,

$$
\text { Precision }=(1 / N) \times \text { Recall } .
$$

$\mathrm{N}$ is recommendation.

In the first scenario, we considered the TSC information from the tiers that did not change and supported all packages that existed on the system. Therefore, the proposed web application considered all the packages (70) during the recommendation process. For a better comparison, we used the average of the precision and recall, which was illustrated in Figures 5 and 6. In the first scenario, the results show that the proposed system has a higher value on both indicators; the collaborative system produced 12.45 recalls and 2.89 precisions. Then, the content-based system produced 14.22 recalls and 3.23 precisions. Additionally, our proposed system produces approximately 16.23 recalls and 3.99 precisions. These results show that the proposed system performs better than the other systems, which improve the rate of acceptable recommendation tour packages based on the customer request. In the second scenario, 5 packages were canceled. The TPA deleted these packages from the RA databases; as a result, these databases were updated, with respect to this disturbance and 65 packages instead of 70 packages were used. Figure 6 shows the average of the indicators, illustrating that the proposed system in scenario 2 had higher values in both results $(R=13.41$ and $P=3.43)$ and performed better than the conventional system.

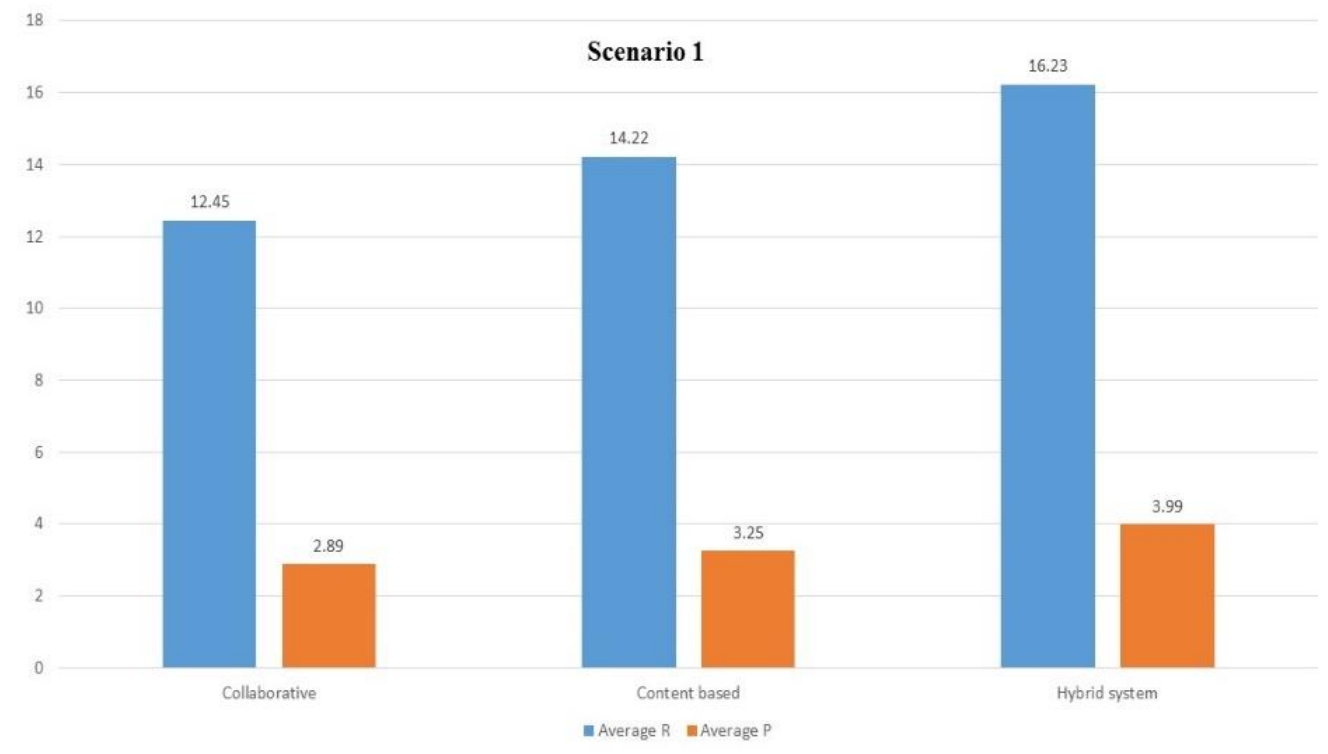

Figure 5. Result of scenario 1. 


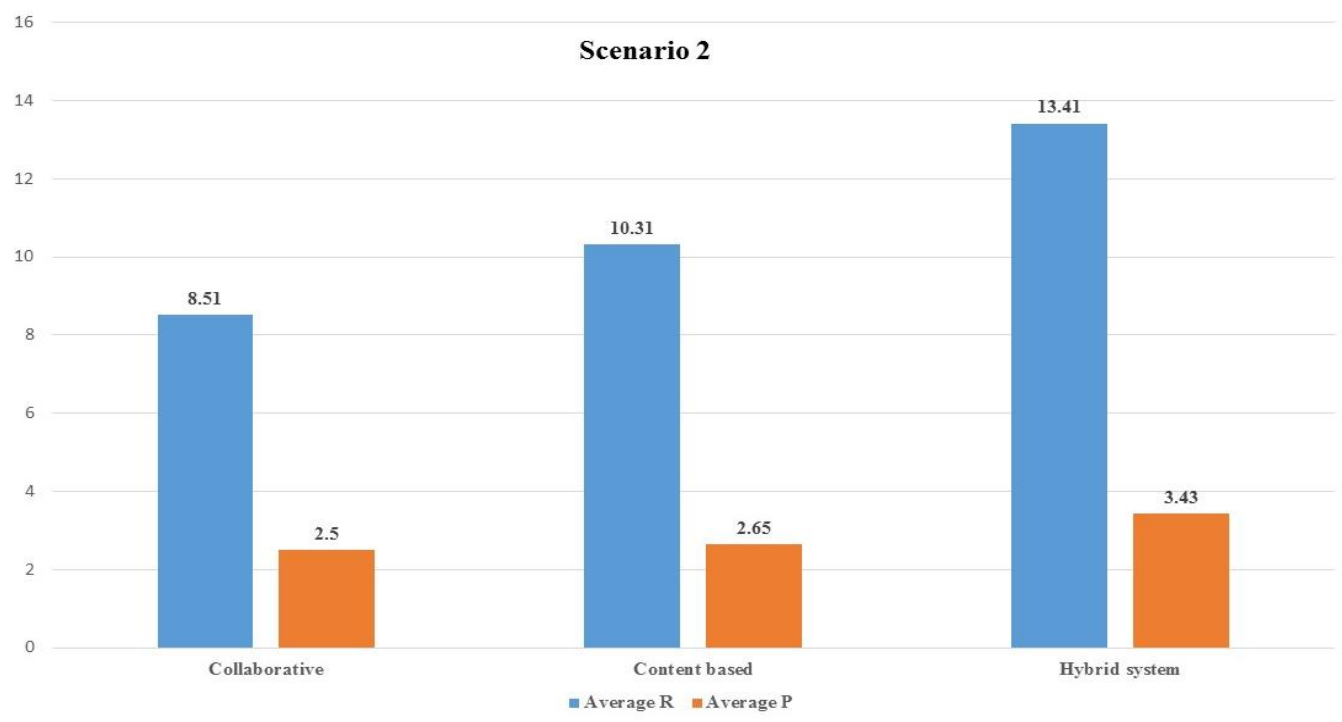

Figure 6. Result of scenario 2.

Tables 3 and 4 provided detail results by highlighted each section on the case study. Therefore, each table contains 10 columns and each of them illustrated result for a section, for example column 1 first 10 customers connected to web application and provided personal information to the web application and based on these information and customer request they received acceptable recommendation from the system. Collaborative-based filtering provides 5.7 packages to a customer-this number this is average of the system and content-based filtering provided 6.2 packages, and our proposed hybrid filtering provided 6.8 tour package to customers, therefore proposed platform improves the rate of acceptable recommendation. As shown in both tables, with the increasing customers data rate of recommendation, packages were improved, but in the proposed platform this rate was better than other approaches. In the second scenario, the result of the last column was significant and proposed platform ( $P=1.9$ and $R=20.3)$ performed much better than collaborative $(P=1.3$ and $R=13.4)$ and content $(\mathrm{P}=1.4$ and $\mathrm{R}=15.1)$.

Table 3. Results for scenario without disturbance.

\begin{tabular}{cccccccccccc}
\hline Type & Indicator & $\mathbf{1}$ & $\mathbf{2}$ & $\mathbf{3}$ & $\mathbf{4}$ & $\mathbf{5}$ & $\mathbf{6}$ & $\mathbf{7}$ & $\mathbf{8}$ & $\mathbf{9}$ & $\mathbf{1 0}$ \\
\hline \multirow{2}{*}{ Collaborative } & $\mathrm{R}$ & 5.7 & 7.8 & 9.8 & 10.7 & 12.1 & 13.6 & 14.7 & 15.4 & 16.9 & 17.8 \\
& $\mathrm{P}$ & 5.7 & 4.6 & 3.2 & 3 & 2.7 & 2.4 & 2.1 & 1.9 & 1.7 & 1.6 \\
\hline \multirow{2}{*}{ Content based } & $\mathrm{R}$ & 6.2 & 9.1 & 11.6 & 13.3 & 14.4 & 15.6 & 16.5 & 17.6 & 18.3 & 19.6 \\
& $\mathrm{P}$ & 6.2 & 3.9 & 3.8 & 3.5 & 3.3 & 2.9 & 2.7 & 2.3 & 2.1 & 1.8 \\
\hline \multirow{2}{*}{ Hybrid system } & $\mathrm{R}$ & 6.8 & 10.1 & 13.5 & 14.7 & 15.8 & 17.2 & 18.9 & 20.5 & 21.4 & 23.4 \\
& $\mathrm{P}$ & 6.8 & 5.7 & 4.6 & 4.1 & 3.8 & 3.5 & 3.3 & 3 & 2.7 & 2.4 \\
\hline
\end{tabular}

Table 4. Results for scenario with disturbance.

\begin{tabular}{cccccccccccc}
\hline Type & Indicator & $\mathbf{1}$ & $\mathbf{2}$ & $\mathbf{3}$ & $\mathbf{4}$ & $\mathbf{5}$ & $\mathbf{6}$ & $\mathbf{7}$ & $\mathbf{8}$ & $\mathbf{9}$ & $\mathbf{1 0}$ \\
\hline \multirow{2}{*}{ Collaborative } & $\mathrm{R}$ & 4.1 & 4.6 & 5.6 & 6.7 & 7.9 & 9.4 & 10.5 & 11.2 & 11.7 & 13.4 \\
& $\mathrm{P}$ & 4.1 & 3.8 & 3.3 & 2.7 & 2.5 & 2.1 & 1.9 & 1.7 & 1.6 & 1.3 \\
\hline \multirow{2}{*}{ Content based } & $\mathrm{R}$ & 4.5 & 5.7 & 7.5 & 9.1 & 10.1 & 11.4 & 12.2 & 13.3 & 14.2 & 15.1 \\
& $\mathrm{P}$ & 4.5 & 3.7 & 3.4 & 3.1 & 2.7 & 2.4 & 2.1 & 1.8 & 1.6 & 1.2 \\
\hline \multirow{2}{*}{ Hybrid system } & $\mathrm{R}$ & 5.7 & 7.1 & 10.5 & 11.7 & 12.8 & 14.2 & 15.9 & 17.5 & 18.4 & 20.3 \\
& $\mathrm{P}$ & 5.7 & 5.2 & 4.1 & 3.7 & 3.3 & 3 & 2.7 & 2.5 & 2.2 & 1.9 \\
\hline
\end{tabular}




\section{Implications}

Based on the evidence underlined in the literature review, smart tourism is a broad category of the tourism industry with a goal of facilitating access to tourism and hospitality products, services, spaces and experiences through ICT-based tools. On the other hand, it also implements innovative and entrepreneurial businesses and fosters the interconnectedness of businesses [75]. Therefore, smart tourism aims to take advantage of advanced information to enable flexibility in services (with considering sustainability and stability) to address a dynamic and global market. In these circumstances, the first challenge is to develop intelligent application for tourism industry to adopt advanced technologies which are the first step of migrating traditional tourism industry to smart tourism industry, therefore, we proposed an agent-based recommendation web application for tours selection, which is capable of improving the recommendation and satisfaction of customers in the tourism industry. The proposed web application developed based on agent technologies and contains five agents with unique features and responsibility in order to create real time data communication and performing suitable filtering mechanism. Therefore, the developed web application created an online platform for recommending tours for customers meanwhile integrated whole tourism sectors. This is accomplished by considering real-time data gathering for different sectors. In this study, we used a hybrid recommendation mechanism for recommending tours for the customer and, multiagent technology used for the design and development of autonomous web application. In this respect, the design system implemented based on the web applicant and provided a graphical interface for the users and hotel manager. The communication between agents developed based on contract net protocol and implemented on the JADE. The proposed platform provided on-demand services for the customers. The proposed system was tested based on case study and compare with other filtering approaches two real based scenarios were consider and based on the results which were formulated by two indicators, proposed can be able to support real time communication and provided better recommendation to customers. In both scenarios, ITRS performed better than others platform such that based on the recall indicator, ITRS improved the acceptable recommendation for customers approximately $20 \%$ (first scenario) and based on the precision indicator, ITRS improved the acceptable recommendation approximately $30 \%$ (second scenario).

\section{Conclusions}

This research paper proposed an agent-based intelligent recommendation software agency by using a hybrid recommendation approach that considered real-time communication. The software designed based on the agent technology, and its architecture was explained in detail. Five agents were defined and implemented via the web application. The communication among agents was established based on the contact net protocol. In this respect, hybrid-based recommendation system was composed of collaborative and content-based approaches.

The main aim of this research paper improves the capability of the software agency by supporting real time data communication and improve the filtering method, the proposed web application was tested based on case study with considering two scenarios i.e., with disturbance and without disturbance. To prove the system's degree of effectiveness, two indicators were defined, and the results showed that the proposed agent-based web application improved the rate of recommendation compared with other platforms, also real time data communication was happening based on Scenario 2 on the whole system, which improved the customization of the system. Furthermore, the proposed system performed better in terms of runtime because the MAS-based system took immediate action to reschedule items whenever the TSC caused strong disturbances. This explains why the recall value on the second scenario was much better than the precision value, because based on real time communication, available packages reduced to 65 . Therefore, in the proposed system, the rate of recommendation of the packages improved and performed better than existing system.

However, this study has some limitations that helped determine the topics for the future studies. The first limitation is the case study; the case study is not tested for real customers. Therefore, it 
needs to be further simulated and tested in the general environment. The second drawback is the communication between the proposed system and the TSC, which was not tested via real hotel sector conditions. Thus, a more realistic condition will be tested in the future. Finally, the developed system used a centralized cloud environment that suffered from trust and third-party problems [76]. As such, future work will have developed blockchain-based data sharing and a platform for smart tourism industry to improve the security and trust of this service-based industry.

Author Contributions: R.H. conducted the research and prepared the initial draft, methodology section; A.V.B. designed the research methodology, software and co-supervised the research; H.A. applied the statistical analysis and co-supervised; Z.L. supervised the project; all of the authors contributed to the data analysis.

Funding: This research was funded by China Postdoctoral Science Foundation under (2018M633008).

Conflicts of Interest: The authors declare no conflict of interest.

\section{Acronyms and Abbreviations}

$\begin{array}{ll}\text { Acronyms } & \text { Definition } \\ \text { RS } & \text { Recommender system } \\ \text { CB } & \text { Content-based filtering } \\ \text { CF } & \text { Collaborative filtering } \\ \text { KBF } & \text { Knowledge-based filtering } \\ \text { MAS } & \text { Multiagent system } \\ \text { ICT } & \text { Information communication technology } \\ \text { ITRS } & \text { Intelligent tourism recommendation agency } \\ \text { TSCA } & \text { Tourism supply chain agent } \\ \text { TPA } & \text { Tour package agent } \\ \text { RA } & \text { Recommendation agent } \\ \text { UA } & \text { User agent } \\ \text { BA } & \text { Broker agent } \\ \text { FIPA } & \text { Foundation for Intelligent Physical Agents } \\ \text { JADE } & \text { Java Agent Development Framework } \\ \text { R } & \text { Recall } \\ \text { P } & \text { Precision }\end{array}$

\section{References}

1. Sebastia, L.; Garcia, I.; Onaindia, E.; Alvarez, C.G. e-Tourism: A tourist recommendation and planning application. Int. J. Artif. Intell. Tools 2009, 18, 717-738. [CrossRef]

2. Spencer, A. ICT and Caribbean Tourism, in Travel and Tourism in the Caribbean; Springer: Berlin/Heidelberg, Germany, 2019; pp. 95-114.

3. Adomavicius, G.; Tuzhilin, A. Toward the next generation of recommender systems: A survey of the state-of-the-art and possible extensions. IEEE Trans. Knowl. Data Eng. 2005, 17, 734-749. [CrossRef]

4. Hlee, S.; Lee, H.; Koo, C. Hospitality and tourism online review research: A systematic analysis and heuristic-systematic model. Sustainability 2018, 10, 1141. [CrossRef]

5. Li, J.; Wu, Q.; Li, X.; Zhu, D. Context-based personalized moblie tourist guide. In Proceedings of the IEEE International Conference on Intelligent Computing and Intelligent Systems, Shanghai, China, 20-22 November 2009.

6. Vansteenwegen, P.; Souffriau, W.; Berghe, G.V.; Oudheusden, D.V. The city trip planner: An expert system for tourists. Expert Syst. Appl. 2011, 38, 6540-6546. [CrossRef]

7. Yeh, D.-Y.; Cheng, C.-H. Recommendation system for popular tourist attractions in Taiwan using Delphi panel and repertory grid techniques. Tour. Manag. 2015, 46, 164-176. [CrossRef]

8. Ferreira, L.; Putnik, G.D.; Cruz-Cunha, M.M.; Putnik, Z. Towards effective tourism dynamic packages. Inf. Resour. Manag. J. 2012, 25, 1-21. [CrossRef]

9. Palos-Sanchez, P.; Saura, J.R.; Reyes-Menendez, A.; Esquivel, I.V. Users Acceptance of Location-Based Marketing Apps in Tourism Sector: An Exploratory Analysis. J. Spat. Organ. Dyn. 2018, 6, 258-270. 
10. Park, D.H.; Kim, H.K.; Choi, I.Y.; Kim, J.K. literature review and classification of recommender systems research. Expert Syst. Appl. 2012, 39, 10059-10072. [CrossRef]

11. Tarus, J.K.; Niu, Z.; Mustafa, G. Knowledge-based recommendation: A review of ontology-based recommender systems for e-learning. Artif. Intell. Rev. 2018, 50, 21-48. [CrossRef]

12. Etaati, L.; Sundaram, D. Adaptive tourist recommendation system: Conceptual frameworks and implementations. Vietnam J. Comput. Sci. 2015, 2, 95-107. [CrossRef]

13. Kim, S.Y.; Kim, J.U.; Park, S.C. The Effects of Perceived Value, Website Trust and Hotel Trust on Online Hotel Booking Intention. Sustainability 2017, 9, 2262. [CrossRef]

14. Gretzel, U.; Sigala, M.; Xiang, Z.; Koo, C. Smart tourism: Foundations and developments. Electron. Mark. 2015, 25, 179-188. [CrossRef]

15. Jovicic, D.Z. From the traditional understanding of tourism destination to the smart tourism destination. Curr. Issues Tour. 2017, 22, 1-7. [CrossRef]

16. Polese, F.; Botti, A.; Grimaldi, M.; Monda, A.; Vesci, M. Social Innovation in Smart Tourism Ecosystems: How Technology and Institutions Shape Sustainable Value Co-Creation. Sustainability 2018, 10, 140. [CrossRef]

17. Borras, J.; Moreno, A.; Valls, A. Intelligent tourism recommender systems: A survey. Expert Syst. Appl. 2014, 41, 7370-7389. [CrossRef]

18. Mahmood, M.A.; El-Bendary, N.; Platoš, J.; Hassanien, A.E.; Hefny, H.A. An Intelligent Multi-Agent Recommender System, in Innovations in Bio-Inspired Computing and Applications; Springer: Berlin/Heidelberg, Germany, 2014; pp. 201-213.

19. Barenji, A.V.; Barenji, R.V.; Roudi, D.; Hashemipour, M. A dynamic multi-agent-based scheduling approach for SMEs. Int. J. Adv. Manuf. Technol. 2017, 89, 3123-3137. [CrossRef]

20. Vatankhah Barenji, A.; Barenji, R.V. Improving multi-agent manufacturing control system by indirect communication based on ant agents. Proc. Inst. Mech. Eng. Part I 2017, 231, 447-458. [CrossRef]

21. Gavalas, D.; Konstantopoulos, C.; Mastakas, K.; Pantziou, G. Mobile recommender systems in tourism. J. Netw. Comput. Appl. 2014, 39, 319-333. [CrossRef]

22. Morais, A.J.; Oliveira, E.; Jorge, A.M. A Multi-Agent Recommender System, in Distributed Computing and Artificial Intelligence; Springer: Berlin/Heidelberg, Germany, 2012; pp. 281-288.

23. Moliner, M.A.; Sánchez, J.; Rodríguez, R.M.; Callarisa, L. Relationship quality with a travel agency: The influence of the postpurchase perceived value of a tourism package. Tour. Hosp. Res. 2007, 7, 194-211. [CrossRef]

24. Wong, C.-K.S.; Kwong, W.-Y.Y. Outbound tourists' selection criteria for choosing all-inclusive package tours. Tour. Manag. 2004, 25, 581-592. [CrossRef]

25. Wong, S.; Lau, E. Understanding the behavior of Hong Kong Chinese tourists on group tour packages. J. Travel Res. 2001, 40, 57-67. [CrossRef]

26. Berne-Manero, C. Reviewing the Online Tourism Value Chain. Adm. Sci. 2018, 8, 48. [CrossRef]

27. Hassannia, R.; Rezapouraghdam, H.; Darvishmotevali, M. An Exploratory Investigation of the HRM Practices in Restaurant Sector: The Case of Famagusta. J. Tour. Gastron. Stud. 2016, 13, 24. [CrossRef]

28. Austin, R.D. The effects of time pressure on quality in software development: An agency model. Inf. Syst. Res. 2001, 12, 195-207. [CrossRef]

29. Bowie, D.; Chang, J.C. Tourist satisfaction: A view from a mixed international guided package tour. J. Vac. Market. 2005, 11, 303-322. [CrossRef]

30. Weaver, P.A.; Weber, K.; McCleary, K.W. Destination evaluation: The role of previous travel experience and trip characteristics. J. Travel Res. 2007, 45, 333-344. [CrossRef]

31. Huang, C.D.; Goo, J.; Nam, K.; Yoo, C.W. Smart tourism technologies in travel planning: The role of exploration and exploitation. Inf. Manag. 2017, 54, 757-770. [CrossRef]

32. Aldebert, B.; Dang, R.J.; Longhi, C. Innovation in the tourism industry: The case of Tourism@. Tour. Manag. 2011, 32, 1204-1213. [CrossRef]

33. Hassannia, R. The Multipurpose Application of Radio Frequency Identification (RFID) in the Tourism Industry: On a Requirement Analysis for Employing RFID Technology in the Hotel Sector. Master's Thesis, Eastern Mediterranean University (EMU)-Doğu Akdeniz Üniversitesi (DAÜ), North Cyprus, Turkey, 2014.

34. Gretzel, U.; Zhong, L.; Koo, C. Application of smart tourism to cities. Int. J. Tour. Cities 2016, 2. [CrossRef] 
35. Amato, F.; Mazzeo, A.; Moscato, V.; Picariello, A. Exploiting cloud technologies and context information for recommending touristic paths. In Intelligent Distributed Computing VII; Springer: Berlin/Heidelberg, Germany, 2014; pp. 281-287.

36. Reyes-Menendez, A.; Saura, J.; Alvarez-Alonso, C. Understanding\# WorldEnvironmentDay user opinions in Twitter: A topic-based sentiment analysis approach. Int. J. Environ. Res. Public Health 2018, 15, 2537.

37. Neuhofer, B.; Buhalis, D.; Ladkin, A. A typology of technology-enhanced tourism experiences. Int. J. Tour. Res. 2014, 16, 340-350. [CrossRef]

38. Gavalas, D.; Konstantopoulos, C.; Mastakas, K.; Pantziou, G. A survey on algorithmic approaches for solving tourist trip design problems. J. Heuristics 2014, 20, 291-328. [CrossRef]

39. Herlocker, J.L.; Konstan, J.A.; Terveen, L.G.; Riedl, J.T. Evaluating collaborative filtering recommender systems. ACM Trans. Inf. Syst. 2004, 22, 5-53. [CrossRef]

40. Su, X.; Khoshgoftaar, T.M. A survey of collaborative filtering techniques. Adv. Artif. Intell. 2009, $2009,421425$. [CrossRef]

41. Lops, P.; de Gemmis, M.; Semeraro, G. Content-based recommender systems: State of the art and trends. In Recommender Systems Handbook; Springer: Berlin/Heidelberg, Germany, 2011; pp. 73-105.

42. Pazzani, M.J.; Billsus, D. Content-based recommendation systems. In The Adaptive Web; Springer: Berlin/Heidelberg, Germany, 2007; pp. 325-341.

43. Pazzani, M.J. A framework for collaborative, content-based and demographic filtering. Artif. Intell. Rev. 1999, 13, 393-408. [CrossRef]

44. Middleton, S.E.; Shadbolt, N.R.; de Roure, D.C. Ontological user profiling in recommender systems. ACM Trans. Inf. Syst. 2004, 22, 54-88. [CrossRef]

45. Trewin, S. Knowledge-based recommender systems. Encycl. Libr. Inf. Sci. 2000, 69, 180.

46. Ricci, F.; Rokach, L.; Shapira, B. Introduction to Recommender Systems Handbook; Springer: Berlin/Heidelberg, Germany, 2011.

47. Barenji, R.V.; Barenji, A.V.; Hashemipour, M. A multi-agent RFID-enabled distributed control system for a flexible manufacturing shop. Int. J. Adv. Manuf. Technol. 2014, 71, 1773-1791. [CrossRef]

48. Batet, M.; Moreno, A.; Sánchez, D.; Isern, D.; Valls, A. Turist@: Agent-based personalised recommendation of tourist activities. Expert Syst. Appl. 2012, 39, 7319-7329. [CrossRef]

49. Schiaffino, S.; Amandi, A. Building an expert travel agent as a software agent. Expert Syst. Appl. 2009, 36, 1291-1299. [CrossRef]

50. Camacho, D.; Borrajo, D.; Molina, J.M. Intelligent travel planning: A multiagent planning system to solve web problems in the e-tourism domain. Auton. Agents Multi-Agent Syst. 2001, 4, 387-392. [CrossRef]

51. Kozlov, D.A. Agent technology in hotel business. J. Environ. Manag. Tour. 2017, 8, 285.

52. Lorenzi, F.; Correa, F.A.C.; Bazzan, A.L.C.; Abel, M.; Ricci, F. A multiagent recommender system with task-based agent specialization. In Agent-Mediated Electronic Commerce and Trading Agent Design and Analysis; Springer: Berlin/Heidelberg, Germany, 2010; pp. 103-116.

53. De Campos, L.M.; Fernández-Luna, J.M.; Huete, J.F.; Rueda-Morales, M.A. Combining content-based and collaborative recommendations: A hybrid approach based on Bayesian networks. Int. J. Approx. Reason. 2010, 51, 785-799. [CrossRef]

54. Chiang, H.-S.; Huang, T.-C. User-adapted travel planning system for personalized schedule recommendation. Inf. Fusion 2015, 21, 3-17. [CrossRef]

55. Al-Shamri, M.Y.H. User profiling approaches for demographic recommender systems. Knowl.-Based Syst. 2016, 100, 175-187. [CrossRef]

56. Fu, X.; Han, G. Trust-embedded information sharing among one agent and two retailers in an order recommendation system. Sustainability 2017, 9, 710. [CrossRef]

57. Guo, Y.; Yin, C.; Li, M.; Ren, X.; Liu, P. Mobile e-Commerce Recommendation System Based on Multi-Source Information Fusion for Sustainable e-Business. Sustainability 2018, 10, 147. [CrossRef]

58. Honey, C.; Herring, S.C. Beyond microblogging: Conversation and collaboration via Twitter. In Proceedings of the 2009 42nd Hawaii International Conference on System Sciences, Big Island, HI, USA, 5-8 January 2009.

59. Buhalis, D.; Deimezi, O. E-tourism developments in Greece: Information communication technologies adoption for the strategic management of the Greek tourism industry. Tour. Hosp. Res. 2004, 5, 103-130. [CrossRef] 
60. Preis, T.; Golke, S.; Paul, W.; Schneider, J.J. Multi-agent-based order book model of financial markets. Europhys. Lett. 2006, 75, 510. [CrossRef]

61. Yan, Y.; Kuphal, T.; Bode, J. Application of multiagent systems in project management. Int. J. Prod. Econ. 2000, 68, 185-197. [CrossRef]

62. Agent-Based Models of Geographical Systems; Heppenstall, A.J.; Crooks, A.T.; See, L.M.; Batty, M. (Eds.) Springer: Berlin/Heidelberg, Germany, 2011.

63. Font, X.; Tapper, R.; Schwartz, K.; Kornilaki, M. Sustainable supply chain management in tourism. Bus. Strateg. Environ. 2008, 17, 260-271. [CrossRef]

64. Labrou, Y.; Finin, T. Semantics for an agent communication language. In International Workshop on Agent Theories, Architectures, and Languages; Springer: Berlin/Heidelberg, Germany, 1997.

65. Fornara, N.; Colombetti, M. Defining interaction protocols using a commitment-based agent communication language. In Proceedings of the Second International Joint Conference on Autonomous Agents and Multiagent Systems, Melbourne, Australia, 14-18 July 2003.

66. Saldaña, J. The Coding Manual for Qualitative Researchers; Sage Publications: Thousand Oaks, CA, USA, 2015.

67. Wang, W.M.; Wang, J.W.; Barenji, A.V.; Li, Z.; Tsui, E. Modeling of individual customer delivery satisfaction: An AutoML and multi-agent system approach. Ind. Manag. Data Syst. 2018. [CrossRef]

68. Sarwar, B.; Karypis, G.; Konstan, J.; Riedl, J. Item-based collaborative filtering recommendation algorithms. In Proceedings of the 10th International Conference on World Wide Web, Hong Kong, China, 1-5 May 2001.

69. Barenji, A.V.; Barenji, R.V.; Hashemipour, M. Flexible testing platform for employment of RFID-enabled multi-agent system on flexible assembly line. Adv. Eng. Softw. 2016, 91, 1-11. [CrossRef]

70. Bellifemine, F.; Poggi, A.; Rimassa, G. JADE-A FIPA-compliant agent framework. In Proceedings of the PAAM, London, UK, 19-21 April 1999.

71. Bellifemine, F.; Poggi, A.; Rimassa, G. Developing multi-agent systems with JADE. In International Workshop on Agent Theories, Architectures, and Languages; Springer: Berlin/Heidelberg, Germany, 2000.

72. Tudorache, T.; Noy, N.F.; Tu, S.; Musen, M.A. Supporting collaborative ontology development in Protégé. In Proceedings of the International Semantic Web Conference, Karlsruhe, Germany, 26-30 October 2008.

73. Woychowsky, E. AJAX: Creating Web Pages with Asynchronous JavaScript and XML; Prentice Hall: Upper Saddle River, NJ, USA, 2007.

74. Varia, J. Architecting for the cloud: Best practices. Amazon Web Services 2010, 1, 1-21.

75. Buhalis, D.; Amaranggana, A. Smart tourism destinations enhancing tourism experience through personalisation of services. In Information and Communication Technologies in Tourism 2015; Springer: Berlin/Heidelberg, Germany, 2015; pp. 377-389.

76. Li, Z.; Barenji, A.V.; Huang, G.Q. Toward a blockchain cloud manufacturing system as a peer to peer distributed network platform. Robot. Comput.-Integr. Manuf. 2018, 54, 133-144. [CrossRef] 